\title{
Terapias génicas: un estudio ético-jurídico
}

INIIGO DE MIGUEL BERIAIN

Becario de Investigación del Departamento

de Filosofía del Derecho, UNED

1.- INTRODUCCIÓN.

El objetivo del presente texto consiste en exponer la problemática asociada a las terapias génicas. A lo largo de las siguientes páginas analizaremos cuidadosamente cómo la genética pude contribuir a combatir muchas de las patologías que afectan al ser humano a través de la modificación o sustitución de los genes implicados en su aparición. Posteriormente, procederemos a estudiar los puntos de conflicto a los que pueden dar lugar desde una perspectiva ético-jurídica, intentando establecer algunos criterios capaces de orientar el desarrollo de unas técnicas que, por su potencial, pueden variar ostensiblemente el futuro de la especie humana.

El tema que ahora nos ocupa goza, por tanto, de una enorme importancia. Tanto es así que son muchos los que piensan que el futuro de la medicina se encuentra, precisamente, en el desarrollo de este tipo de prácticas. Esta idea, que a primera vista parece un tanto exagerada, recupera, no obstante, toda su vigencia si tenemos en cuenta que las terapias génicas son las únicas que tienen una posibilidad real de atacar la 
enfermedad en su misma raíz, esto es, desde su propia base genética. El problema es que, por el momento, los únicos resultados fiables que hemos conseguido obtener en este campo vienen del lado del diagnóstico. Así, si bien hoy en día es perfectamente posible detectar muchas patologías a través del estudio del mapa génico de una persona concreta, resulta mucho más complicado efectuar el segundo paso, esto es, aplicar una terapia efectiva a nivel génico que elimine el mal en cuestión.

Este evidente desequilibrio ha hecho que hayan surgido cuestiones de difícil respuesta en el ámbito de la medicina y de la ética. Así, la falta de unas terapias génicas efectivas ha llevado a que, en muchos casos, sea la medicina tradicional quien, partiendo de los datos obtenidos por el análisis, se encargue de adoptar las medidas necesarias para impedir o retrasar la aparición de las patologías anunciadas por los genes. Se produce, de esta forma, un incremento espectacular de la importancia de la medicina preventiva, que se ha convertido en una de las ramas más importantes de dicha ciencial.

La aparición de este tipo de técnicas ha suscitado, no obstante, también algunas nuevas polémicas. Así, la aparición del diagnóstico génico ha traído importantes consecuencias en el campo de la reproducción asistida. De este modo, y en un breve intervalo de tiempo será posible realizar un estudio preciso de cada embrión, analizando en cada caso las probabilidades de contraer enfermedades concretas, lo cual, como es obvio, puede llevarnos a una posterior actuación, ya sea curativa o meramente selectiva. De acuerdo con la primera idea, la aparición de ciertos tipos de enfermedades en el mapa génico embrionario debería traer como consecuencia la aplicación de las terapias oportunas. Sin embargo, un camino más sencillo y menos costoso, desde el punto de vista de la asignación de recursos, parece ser el de eliminar todos aquellos embriones que presenten problemas, implantando exclusivamente los que respondan a las expectativas desarrolladas por sus progenitores. Se abre así, de un modo inevitable, una amplia puerta para nuevas formas de eugenesia, con todos los peligros que esta fórmula encierra. 
De este modo, no podemos olvidar que existe la posibilidad de que, con el transcurso del tiempo, las terapias génicas acaben ocasionando la aparición de toda una ingeniería génica que vaya más allá de las finalidades meramente terapéuticas para adentrarse de lleno en el terreno de la eugenesia. En lo que a ello respecta, debemos pensar que, una vez desarrolladas las técnicas de modificación génica desde una visión puramente terapéutica, resulta muy sencillo utilizar estas mismas prácticas para otras finalidades mucho menos recomendables. Se abre así, de una forma muy difícil de evitar, una puerta a lo que algunos autores han denominado "niños a la carta", , con todas las terribles implicaciones que semejantes prácticas pueden traer consigo.

A lo largo del presente texto, y dadas las limitaciones de espacio que inevitablemente nos acompañan, nos permitiremos obviar algunos de los problemas que ya hemos expuesto en esta introducción, centrándonos exclusivamente en las cuestiones que atañen a las terapias génicas en sí mismas. El motivo de nuestra determinación es que muchas de las cuestiones arriba planteadas no se encuentran directamente relacionadas con estas técnicas como tales, sino, más bien, con las carencias de las que éstas todavía adolecen. De este modo, por ejemplo, si existe un problema con los embriones defectuosos es porque todavía no hemos desarrollado terapias génicas baratas que puedan combatir adecuadamente sus patologías. Otras cuestiones, como la posibilidad de que se desarrolle una ingeniería génica eugenésica, no son, desde nuestra perspectiva, tanto un problema de las terapias génicas como del uso incorrecto de una técnica concreta, de por sí inocua.

En lo que se refiere al enfoque sistemático, comenzaremos nuestro estudio con el análisis de lo que las terapias génicas son. A continuación, proseguiremos con un estudio histórico de su desarrollo que incluya la situación en la que se encuentran en este momento, de tal forma que sea posible tener bien presente cuáles son exactamente las opciones que ahora mismo nos ofrecen estas técnicas y cuáles pueden llegar a otorgarnos en un futuro. Posteriormente, continuaremos con el estudio, des- 
de la perspectiva de la ética, de los diferentes tipos de terapias génicas, distinguiendo claramente entre unos y otros. Por último, mostraremos el estado en que se encuentra ahora mismo la legislación aplicable a esta materia, centrándonos especialmente en el marco de la UNESCO y del Consejo de Europa.

\section{2.- TERAPIAS GÉNICAS}

Antes de adentrarnos en la cuestión que ahora nos ocupa, debemos decir que el campo de las terapias génicas debe englobarse en otro mucho más amplio, el que corresponde a la ingeniería genética. Por eso mismo, creemos más adecuado dedicar unas breves líneas a toda esta nueva disciplina. En lo que a ello respecta, señalaremos, para empezar, que por ingeniería genética debe entenderse "una tecnología cuya finalidad es mejorar la herencia genética de los seres vivos mediante la manipulación de su código genético"3. Nos encontramos, por tanto, con que los elementos fundamentales de esta nueva disciplina son, de un lado, un saber instrumental completamente nuevo, esto es, el descubrimiento de una técnica que permite modificar nuestros genes; de otro, un objetivo claramente eugenésico: mejorar la carga genética presente en los seres humanos. Ahora bien, si la parte técnica no plantea ningún dilema a la ética, ya que las herramientas disponibles para la ciencia son, en sí mismas, inocuas, la finalidad que se busca con estas prácticas no podrá nunca dejar indiferentes a todos aquellos que sientan preocupaciones morales. Por eso mismo, debe trazarse una línea divisoria muy profunda entre las terapias génicas, rama de la ingeniería genética que goza de una finalidad eminentemente terapéutica, y todas las demás prácticas a las que puedan dar origen estas mismas técnicas, que han de ser objeto de un análisis diferente, en cuanto a que su objetivo es completamente diverso, y diferentes han de ser también las consideraciones éticas efectuadas en torno a ellas ${ }^{4}$. Por eso mismo, y como ya hemos se- 
ñalado en nuestra introducción, en el presente texto, y dadas las inevitable limitaciones de espacio que acompañan a toda obra de este tipo, omitiremos el análisis de las prácticas de ingeniería genética que no tengan una finalidad terapéutica, posponiéndolo a obras posteriores.

Entrando ya en lo que se refiere específicamente a las terapias génicas, comenzaremos por decir que éstas pueden definirse como "todas aquellas que utilizan la administración deliberada de material genético en un paciente humano con la intención de corregir un defecto genético específico"5. La idea fundamental de la que parten estas técnicas es, por consiguiente, que muchas de las patologías que afectan al ser humano tienen una base genética. Por eso mismo, su objetivo básico consiste en suprimir la modificación genética producida por una patología determinada. Ello no obstante, la problemática, tanto técnica como ética, que encierra su puesta en funcionamiento hace que resulte necesario un amplio y abierto debate público acerca de esta controvertida cuestión.

Como ya hemos anticipado en nuestra introducción, desde el punto de vista de la técnica, el mayor problema con el que nos enfrentamos ahora mismo es que existe una grave descompensación entre lo que podemos saber y lo que podemos hacer. Así, y si bien desde el campo de la diagnosis parece evidente que ya es más que factible alcanzar resultados fiables, todavía no se ha logrado diseñar un método efectivo de modificación genética. De este modo, nos encontramos con que las terapias génicas aún no gozan de la madurez suficiente como para hacernos olvidar las terapias tradicionales ${ }^{6}$. Por otra parte, y desde la perspectiva de la ética, es obvio que la problemática que plantean unas prácticas que, llegado el caso, pueden alterar completamente la vida de la especie humana, es ardua y compleja. Así, como tendremos ocasión de contemplar más adelante, la discusión moral tendrá que enfrentarse a menudo a dilemas de difícil solución, y que tienen mucho que ver con la ponderación de principios como el de beneficencia, autonomía, justicia o no maleficencia, ya clásicos en la Bioética. Ello no obstante, antes 
de introducirnos en esta agria polémica, debemos exponer cuál ha sido realmente la historia de las terapias génicas y cuáles son las posibilidades que ahora mismo nos ofrecen, de tal modo que podamos hacernos una idea de lo que pueden depararnos en un futuro. A esta tarea dedicaremos el próximo epígrale.

\section{3.- HISTORIA DE LAS TERAPIAS GÉNICAS}

Lo primero que uno debe tener presente cuando empieza a analizar cualquier cuestión relacionada con las terapias génicas es que su nacimiento se ha producido hace verdaderamente muy poco tiempo, tan poco que todavía cualquier afirmación roza el terreno de la conjetura. Los primeros experimentos encaminados a eliminar un gen en un mamífero, más concretamente en un ratón, tuvieron lugar hace apenas veinte años, en los años ochenta del pasado siglo ${ }^{7}$. En lo que respecta a los seres humanos, las primeras pruebas son todavía más recientes. Así, no fue sino en 1988 cuando Steven Rosemberg utilizó por primera vez esta clase de prácticas para tratar un cáncer avanzado, experimento de cuyo resultado real no hay datos fiables, debido a la propia dificultad de valoración que ofrece cualquier terapia en casos pertenecientes al campo de la oncología en los que la enfermedad se encuentra ya avanzada.

El siguiente experimento lo encontramos un poco después, en septiembre de 1990, cuando un equipo americano guiado por F. Anderson y M. Blaese trató mediante dicha técnica a una niña de cuatro años de edad, Ashanti Desilva, que padecía una patología sumamente extraña llamada "deficiencia de la adenosina deaminasa" (ADA, de acuerdo con sus siglas en inglés), también conocida como "enfermedad de la burbuja", porque obliga a quienes la padecen a vivir dentro de una burbuja de plástico que los protege de los gérmenes ${ }^{8}$. El objetivo del experimento citado consistió en inyectar dentro del cuerpo de su paciente más de mil millones de células que contenían las dosis normales de esta proteína a 
través de unos virus inertes que actuaban como vectores o vehículos de transmisión'. Con ello se esperaba que, a largo plazo, la paciente superase su discapacidad.

Los resultados del citado experimento fueron, en primer término, claramente alentadores. Sin embargo, poco después se empezó a ver que había muchos motivos por los que dudar de que su éxito fuera tan notable como se pensó inicialmente. A los cinco años de su inicio, el mismo equipo que había llevado a cabo el intento tuvo que admitir que, si bien algunas de las células trasplantadas continuaban produciendo ADA, la terapia adoptada no había conseguido eliminar la patología, tal y como hubiera sido deseable ${ }^{10}$. Poco después, un equipo italiano que había llevado a cabo unas pruebas muy similares a las del experimento americano llegó a las misma conclusiones finales ${ }^{11}$. Otro destacado ensayo, llevado a término por James Wilson en torno a otra enfermedad claramente genética, como la hipercolesterolemia familiar, tampoco consiguió efectos duraderos entre los afectados ${ }^{12}$.

A pesar de estos fracasos, a lo largo de los años 90 se continuó con la investigación, de tal forma que hasta 3000 pacientes que padecían enfermedades como la fibrosis quística, la hemofilia, la distrofia muscular, el SIDA o el cáncer, entre otras, se sometieron a terapias génicas. Así, hasta el 25 de mayo de 2000 se habían realizado 425 experimentos con terapias génicas sobre 3476 pacientes. De todos ellos, 279 se hallaban directamente relacionados con el estudio del cáncer, mientras que 55 se referían a enfermedades monogénicas. El resto, 33 , se realizaron sobre enfermos que padecían patologías infecciosas, principalmente SIDA ${ }^{13}$. Los resultados obtenidos con todos estos experimentos fueron, no obstante, sumamente desalentadores ${ }^{14}$. A largo plazo, todos los logros cosechados en primera instancia desaparecían por motivos desconocidos, de tal modo que era imposible alcanzar un resultado efectivo de cara al paciente. A ello se había de añadir que, en muchos casos, las técnicas empleadas generaban graves problemas, como la aparición de fuertes procesos febriles, a menudo acompañados de inflamaciones, que, en buena 
parte de los casos, obligaban a la suspensión del tratamiento ${ }^{15}$. El punto culminante de esta racha de noticias negativas tuvo lugar en septiembre de 1999, cuando un chico de Arizona de dieciocho años de edad, aquejado de una patología denominada "deficiencia de ornitina transcarbamilasa", se sometió voluntariamente a terapia génica en la Universidad de Pennsylvania, cuyo equipo era dirigido por el ya mencionado James Wilson. El experimento, por causas difíciles de prever a priori, ocasionó al paciente una terrible inflamación que acabó causándole la muerte el 17 de septiembre ${ }^{\mathrm{j} 6}$. Fue el momento más bajo de la aplicación de las terapias génicas.

En los últimos tiempos, no obstante, las circunstancias parecen haber cambiado significativamente. El origen de esta nueva esperanza hay que encontrarlo en un equipo francés de investigación dirigido por Alain Fischer ${ }^{17}$. Este equipo consiguió en un experimento desarrollado en el año 2000 el primer resultado verdaderamente exitoso contra una enfermedad genética gracias a las terapias génicas. Se trataba de un caso en el que los pacientes sometidos al tratamiento ${ }^{18}$ padecían de inmunodeficiencia combinada grave XI, patología muy similar a la deficiencia de la adenosina deaminasa, que se caracteriza por la imposibilidad de desarrollar células $\mathrm{T}$, componentes esenciales del sistema inmunológico humano. El tratamiento consistió en este caso en la extracción de células de la médula ósea que, posteriormente, se reconstituyeron genéticamente de manera que fueran capaces de desarrollar células T. Cinco días más tarde, se devolvieron a su lugar de origen, utilizando un vector retroviral, con la esperanza de que fueran capaces de desarrollar las células ansiadas. Diez meses después de llevar a cabo esta operación, el sistema inmunológico de cuatro de los pacientes tratados se hallaba restaurado, de tal modo podían llevar vida normal sin recibir ningún tipo de medicación ${ }^{19}$. 
4.- TIPOLOGÍA DE TERAPIAS GÉNICAS.

La radical novedad de las terapias génicas hace que resulte tremendamente complicado establecer una única clasificación que las englobe a todas desde un único punto de vista. En su lugar, procederemos a efectuar varias distinciones en función de parámetros diversos, como la forma en que se apliquen, la clase de línea celular a la que afecten, el lugar donde se realice la intervención, etc.

Así, y de acuerdo con la forma en que tiene lugar la aplicación de la práctica, se puede hablar de métodos físicos, químicos y métodos que proceden a la utilización de vectores virales ${ }^{20}$. Estas técnicas, sin embargo, no cuentan todas con la misma efectividad. De entre ellas, parece gozar de grandes expectativas la que parte de una versión modificada de retrovirus, como el virus del SIDA, como vehículo portador de las células modificadas genéticamente ${ }^{21}$. Estos no son, sin embargo, los únicos virus que se usan, sino que a menudo se emplean también adenovirus y virus adenoasociados, aun cuando todavía no está claro cuál será su utilidad final ${ }^{22}$. Otras estrategias, por su parte, se fundamentan en la utilización de liposomas o de $\mathrm{ADN}$ puro transferidos al paciente por infiltración, prescindiendo, por tanto, completamente del papel mediador de los virus y evitándose así todos los problemas que éstos traen consigo $^{23}$. Una posibilidad muy parecida a es la de crear cromosomas humanos artificiales, grandes fragmentos de $\mathrm{ADN}$ que permanecen estables en el núcleo celular, de tal forma que pueden transportar cualquier gen que se desee y que tampoco presentan ninguno de los efectos secundarios de los virus ${ }^{24}$.

Una segunda clasificación es la que emplea como criterio distintivo el lugar en el que se produce efectivamente la actuación sobre el gen. En función de este parámetro, se puede hablar de tres tipos de terapias génicas $^{25}$ : terapias celulares ex vivo, in situ e in vitro ${ }^{26}$. Las primeras son aquellas que tienen lugar en el laboratorio sobre células extraídas del paciente que, posteriormente, le serán reintroducidas. Las segundas, es- 
to es, las denominadas in situ, introducen directamente una modificación genética en el propio órgano o tejido defectuoso del paciente. Las terapias génicas realizadas in vitro, por último, son las que utilizan unos vectores para introducir los genes terapéuticos en las células defectuosas a través del torrente circulatorio, mediante inyección intravenosa, por ejemplo.

A su vez, y de acuerdo con la forma en que la terapia génica pretende alterar el $\mathrm{ADN}$, se puede establecer una distinción entre las que introducen en las células una versión sana del gen defectuoso pero sin llegar a alterar éste, las que intentan modificar el gen defectuoso mediante mutagénesis dirigida, y las que, tratan de sustituir el gen defectuosos por su versión normal ${ }^{27}$. Todas estas diversas variantes, aun con diferencias sustanciales en el procedimiento, comparten sin embargo una característica común, cual es la de intentar aportar al paciente una solución que compense los efectos nocivos de una alteración en su información genética. La única de entre todas ellas que proporciona una táctica ideal para obtener un resultado óptimo es la última, ya que permite alterar directamente el $\mathrm{ADN}$ defectuoso en el lugar en el que éste se encuentra, esto es, el interior del núcleo celular ${ }^{28}$. Si el desarrollo de las técnicas alternativas descritas se ha producido ha sido, exclusivamente, porque no era posible vislumbrar una forma de llevar a la práctica esta segunda posibilidad ${ }^{29}$. Sin embargo, en los últimos tiempos una empresa norteamericana llamada Kimeragen parece haber descubierto un método fiable para efectuar esta operación ${ }^{30}$.

Ello no obstante, la clasificación más importante es aquella que divide las terapias génicas en dos grupos principales en función de la línea celular que se ve afectada por ellas. En un primer conjunto se incluyen todas las que intervienen sólo sobre las células de la línea somática, de modo que los cambios a los que dan lugar no se transmiten a la descendencia del paciente. Son las llamadas terapias génicas somáticas. Existe, en cambio, un segundo grupo de técnicas que, al contrario que las anteriores, operan sobre las células sexuales y, por consiguiente, las 
transformaciones que producen pasan a las siguientes generaciones, esto es, a los descendientes del enfermo, razón por la que se denominan terapias génicas germinales ${ }^{31}$. En los próximos apartados será, precisamente esta clasificación la que orientará nuestro estudio ético. El motivo de esta decisión sistemática es que será este criterio, la posibilidad de que las modificaciones se transmitan a la descendencia o no, el que marque una distinción verdaderamente nítida desde el punto de vista de la moral, como tendremos ocasión de ver más adelante.

\section{5.- LAS TERAPIAS GÉNICAS DESARROLLADAS SOBRE LA LÍNEA SOMÁTICA}

Entrando ya a analizar las terapias génicas, señalaremos antes que nada que, ya desde el primer momento, su nacimiento estuvo envuelto en el tipo de polémica que suele rodear a los grandes hitos en la historia de la ciencia. Ya entonces fueron muchos los que se opusieron a su puesta en práctica desde la idea de que el hombre no debía inmiscuirse en un terreno que no le era propio o, si se prefiere, que no debía "jugar a ser Dios"32. Así, ya a principios de los años ochenta Jeremy Rifkin expuso la idea de que el hombre no tiene ningún derecho a alterar la naturaleza $^{33}$. Esta postura fue, a su vez, respaldada por muchos de los representantes de las principales religiones, que veían en las intervenciones sobre el genoma un grave peligro de que el hombre intentara usurpar el lugar de Dios ${ }^{34}$. La conclusión que ambas variantes sobre una misma postura extraían era que no se debía permitir la continuación de estos experimentos por el gravísimo riesgo que ello podría conllevar para el futuro de la humanidad ${ }^{35}$.

La postura ahora enunciada, por suerte o desgracia, no ha obtenido un respaldo firme desde el campo de la Bioética. Más bien al contrario, son muchas las voces que se han alzado para afirmar que el hecho de que una conducta humana manipule a su antojo la naturaleza no es motivo suficiente para considerarla éticamente mala. Lo contrario sería 
tanto como lesionar de una forma esencial el postulado de nuestra libertad, que demanda, también, la posibilidad de variar el medio en que desarrolla su existencia el ser humano, aun cuando para ello sea necesario, como no podría ser menos, un consenso amplio entre los representantes de la humanidad en su conjunto ${ }^{36}$.

Por nuestra parte, nos permitiremos decir que, sea cual sea la posición que se halle más cercana a la verdad, lo cierto es que, desde una ética de mínimos, esto es, una ética que busque un acuerdo social lo más amplio posible que permita una convivencia adecuada, no parece sensata una prohibición absoluta de las terapias génicas somáticas sobre la base de un argumento como el que acabamos de exponer. Demasiados colectivos esperan ansiosos los resultados de este tipo de prácticas como para recomendar lo contrario por un motivo tan frágil. En lo que a este punto respecta, resulta necesario recordar aquí que las terapias génicas desarrolladas sobre la línea somática afectan, exclusivamente, al sujeto que se somete a ellas. Esto, por su parte, implica que su prohibición generalizada sea contemplada, desde muchas fuentes, como una intromisión inaceptable en la esfera de la libertad individual, como una conducta frontalmente contraria a los postulados del principio de autonomía. Cabe, por tanto, concluir que, en el caso de que una persona adulta otorgue un consentimiento informado a una intervención de este tipo, es muy dilícil justificar una quiebra de su voluntad por motivos tan poco sólidos, desde la perspectiva de una ética de mínimos, como la apelación a la idea de "jugar a ser Dios".

Este tipo de consideraciones, perfectamente válidas en el caso de personas adultas deben, no obstante, y desde nuestra perspectiva, excluirse en el supuesto de que sean embriones humanos tempranos quienes se sometan a la práctica ahora analizada. El motivo de esta negación es bien sencillo: si es perfectamente cierto que a partir de un cierto grado de desarrollo humano se pueden distinguir perfectamente ambas líneas, somática y germinal, también lo es que en los primeros días de nuestra existencia, éstas se hallan confundidas, de tal modo que, al menos con las tecnologías que ahora mismo poseemos, resulta casi imposible estar 
seguros de que podemos modificar una de ellas sin afectar a la otra al mismo tiempo. Por eso mismo, cuando se trate de embriones tempranos, perderán consistencia muchas de las afirmaciones que ahora mismo acabamos de realizar, porque, en este caso, la línea afectada por esta clase de prácticas puede ser, de una forma inevitable, la germinal. En consecuencia, esperaremos al siguiente apartado de este trabajo para dar una respuesta a esta controvertida cuestión.

Un segundo argumento al que se ha recurrido para oponerse a la puesta en práctica de las terapias génicas es la completa falta de un medio científicamente aceptable de ponerlas en práctica. En lo que a ello respecta, no está de más recordar que, en los primeros tiempos, los experimentos se saldaron con una serie de estrepitosos fracasos. Consecuentemente, hubo quienes consideraron que continuar con esta línea de investigación atentaba contra el principio de justicia, en el sentido de que se estaba produciendo un grave despilfarro de los medios económicos disponibles, siempre escasos ${ }^{37}$. De este modo, y según su punto de vista, debía producirse un cambio en la orientación de la investigación médica que postergara las terapias génicas en beneficio de otro tipo de actuaciones más provechosas ${ }^{38}$.

Sin intentar restar coherencia a este tipo de argumentos, nos permitiremos, no obstante, señalar que la situación en la que ahora mismo nos encontramos no tiene mucho que ver con la que existía hace apenas tres años. Así, debemos reiterar aquí que las pruebas efectuadas entre 1999 y 2002 nos han traído nuevas e interesantes perspectivas en cuanto a la aplicabilidad de las terapias génicas ${ }^{39}$. Cabe, además, recordar que es obvio que un desarrollo adecuado de estas terapias pueden suponer, a largo plazo, un inmenso ahorro de recursos para nuestros sistemas sanitarios. De esta forma, y aun teniendo en cuenta los estrictos postulados del principio de justicia, parece claro que debemos continuar con el desarrollo de las terapias génicas en la línea somática.

El tercero de los argumentos que se suelen esgrimir en contra de la aplicación de las terapias génicas sobre la línea somática hace referen- 
cia a la existencia de graves riesgos para las personas que se sometan a ellas. El desconocimiento que todavía existe acerca de su funcionamiento hace que en ciertas ocasiones se produzcan graves efectos secundarios e, incluso, en casos aislados, la muerte del paciente ${ }^{40}$. Por tanto, continuar aplicándolas contradiría el postulado de no maleficencia. Esta primera evidencia debe, a nuestro juicio, ser convenientemente matizada por otra clase de consideraciones. Así, y en primer lugar, es obvio que en todas las terapias experimentales, sean de la clase que sean, existe un cierto riesgo que no puede ser eliminado fácilmente. De otro lado, e íntimamente relacionado con lo que acabamos de decir, es también evidente que debe realizarse una cuidadosa comparación entre los riesgos que implica utilizar una terapia génica y los resultados que pueden obtenerse a través de ella o de otras terapias. Así, por ejemplo, no es lo mismo utilizar una terapia génica en el caso de un paciente terminal de cáncer, para el que ya se ha descartado cualquier posibilidad de tratamiento tradicional, que emplearla en una enfermedad que goza ya de fácil solución mediante la administración de fármacos o prácticas habitualmente utilizadas. Por otra parte, no podemos olvidar que abandonar completamente esta línea de investigación podría constituir un grave atentado contra el principio de beneficencia, en el sentido de que cada día está más claro que hay algunas patologías que sólo pueden ser tratadas a través de este tipo de técnicas. En consecuencia, suspender repentinamente toda la experimentación en torno a las terapias génicas somáticas supondría tanto como abandonar a su suerte a muchas personas enfermas cuya única posibilidad real de recuperación pasa por este tipo de prácticas ${ }^{41}$. A todo lo anterior debemos añadir, en cualquier caso, que una objeción de este tipo no supone, en verdad, una oposición frontal a estas prácticas sino, en todo caso, el establecimiento de una moratoria hasta el instante en que puedan ponerse en práctica de una forma más segura.

La conclusión más inmediata de todo lo que acabamos de exponer no puede ser otra, a nuestro juicio, que la aceptación, en general, de las te- 
rapias génicas somáticas. Una mínima ponderación de principios bioéticos básicos como los de autonomía, beneficencia y justicia debe llevarnos a pensar que, aun cuando los costes que pueda traer consigo la prosecución de las actuales líneas de investigación sean muy elevados ${ }^{42}$, la posibilidad de salvar miles de vidas gracias a sus resultados debe ser motivo suficiente para proseguir con el esfuerzo y para permitir que muchas personas puedan optar libremente por la utilización de este tipo de terapias $^{43}$.

Esta recomendación está afectada, no obstante, por múltiples y variadas variables. Así, si alguien llegara a demostrar que resulta imposible intervenir en la línea somática sin afectar al mismo tiempo a la línea germinal, tendríamos que replantearnos toda la cuestión ${ }^{44}$. De otra parte, y aun cuando este riesgo sea definitivamente superado, es obvio que la realización de este tipo de prácticas debe hallarse siempre supeditada al cumplimiento de una serie de requisitos, propios de la buena práctica médica. No se puede pensar en unas terapias génicas que no garanticen la confidencialidad de sus resultados, o la ponderación de los riesgos sobre los afectados. Por último, hay que hacer notar que, tratándose ésta de una terapia experimental, el consentimiento del afectado debe ser contemplado como requisito absolutamente necesario. La creación de comités de bioética al efecto, o de cualquier otro elemento similar sería, a buen seguro, una garantía más que necesaria para evitar que pudieran producirse excesos a este respecto.

\section{6.- TERAPIAS GÉNICAS DESARROLLADAS SOBRE LA LÍNEA GERMINAL}

Aun cuando el presente apartado está dedicado a las terapias desarrolladas sobre la línea germinal, no podemos pasar por alto que, si durante tanto tiempo se ha manifestado una fuerte oposición a las que afectan a la línea somática ha sido porque, en el fondo, muchos temían que su adopción no fuera sino un primer paso que abriera la puerta ha- 
cia otro tipo de prácticas mucho más peligrosas. De este modo, y utilizando la ya famosa línea argumentativa que los americanos suelen denominar "pendiente resbaladiza" 45 , había quienes afirmaban que la aceptación de las terapias sobre la línea somática traería consigo inevitablemente la de las terapias sobre la línea germinal y la de la ingeniería genética en su conjunto.

Lo más curioso de todo es que este temor, que a menudo resulta más producto de una vocación alarmista que de una visión realista de los hechos, ha sido fomentado por todos aquellos que, aprovechando la aceptación de la que parecían gozar los primeros experimentos de terapias génicas, intentaron abogar por una ampliación de los mismos a la línea germinal. Así, en una fecha tan temprana como diciembre de 1991, el doctor Zimmerman solicitó en una revista americana la extensión de los experimentos relacionados con las terapias génicas a la línea germinal ${ }^{46}$. A fin de justificar su petición, adujo dos motivos distintos: en primer lugar, puso de relieve la inevitable certeza de que las terapias génicas en la vía somática elevarían la esperanza de vida de seres humanos portadores de esas enfermedades. A su vez, y dado que el proceso de curación no se extendería a su línea germinal, sus patologías se transmitirían inevitablemente a su descendencia ${ }^{47}$. Con el tiempo, este problema podría extenderse a importantes cantidades de miembros de la especie humana, ya que la capacidad estabilizadora de la selección natural perdería fuerza debido a las nuevas técnicas de curación ${ }^{48}$. Por eso mismo, la utilización exclusiva de terapias génicas que no fueran más allá de la línea somática podría ser, desde su perspectiva, perjudicial para la especie humana. De otro lado, el investigador citado hacía referencia a un motivo meramente técnico: a su juicio, las terapias génicas sobre la línea somática nunca podrían dar respuestas adecuadas a todas aquellas patologías que afectaran a tejidos sólidos, órganos y funciones dependientes de la estructura, labor que, sin embargo, podrían desempeñar las terapias desarrolladas sobre la línea germinal ${ }^{49}$.

A estos dos motivos médicos se añadía un tercero de marcada tendencia economicista: las terapias efectuadas sobre la línea germinal po- 
drían contribuir a disminuir el gasto sanitario en mucho mayor medida que las efectuadas sobre la línea somática, porque mientras las primeras erradicaban la enfermedad definitivamente, las segundas sólo lo hacían de forma temporal, es decir, en el caso de un individuo aislado, pero no en el de toda la especie humana. ${ }^{50}$ Por estas razones, y siguiendo estrictamente el criterio de beneficencia y el de justicia en la distribución de los recursos, Zimmerman consideraba que era necesario potenciar las investigaciones en torno a las terapias que afectaban a la línea germinal.

A todo lo manifestado por el autor citado debemos añadir por nuestra parte que, aunque a menudo parezca que lo olvidamos, es bastante probable que para muchas de las patologías que afectan a los embriones tempranos no haya otra solución que acudir a unas terapias génicas que, muy probablemente, acabarán extendiéndose a su línea germinal. Ello no obstante, algunos autores han repuesto a este argumento que una solución alternativa puede ser, sencillamente, no implantar los embriones aquejados de esta clase de patologías ${ }^{51}$. Evidentemente, así se evita el riesgo de afectar a la línea germinal con una terapia génica incorrecta, pero al coste de dejar morir al afectado. Evidentemente, este tipo de consideraciones abre la puerta a una agria polémica de difícil respuesta. De cualquier forma, es obvio que en las circunstancias ahora apuntadas el estatuto que otorguemos al embrión será definitivo a la hora de dar una respuesta adecuada a este problema.

Dejando por un momento aparte este último y polémico punto que acabamos de exponer, nos permitiremos dar una breve respuesta a las tesis de Zimmerman. En lo que a ello respecta, debemos señalar, antes que nada, que el problema básico que implica el planteamiento del autor citado radica en que la genética todavía es una ciencia relativamente joven, siendo así que aún quedan grandes progresos que realizar antes de comenzar a dominar adecuadamente las consecuencias de algunas de sus aportaciones. Consiguientemente, no podemos dejar de resaltar que existe un desconocimiento casi absoluto de los efectos que podría tener la aplicación indiscriminada de las terapias génicas sobre 
la línea germinal para la especie humana. Por eso mismo, una actuación demasiado precipitada podría traer consecuencias ahora mismo insospechables, no sólo para los seres humanos que ya existen sino, al mismo tiempo, para el futuro de la seres todavía no nacidos que, a su vez, nunca habrán tenido oportunidad de pronunciarse sobre esta materia ${ }^{52}$. De otra parte, es necesario resaltar que el mecanismo de actuación de nuestros genes no es, por desgracia, tan sencillo como para que podamos aventurarnos a eliminar uno de ellos sólo porque, a primera vista, parece tener efectos nocivos para la vida de aquellos que lo poseen. De hecho, los nuevos descubrimientos nos están demostrando que hay muchos genes que pueden tener un doble efecto, positivo o negativo, dependiendo de muchas circunstancias. Por eso mismo, eliminarlos definitivamente resulta, desde nuestra perspectiva, demasiado aventurado ${ }^{53}$.

Por otra parte, y en lo que se refiere al presunto ahorro que podríamos lograr utilizando este tipo de terapias, debemos reflejar aquí que, en contradicción con lo manifestado por Zimmerman, hay quienes han declarado que, desde su perspectiva, resulta demasiado aventurado confiar en unas terapias que, a fin de cuentas, nadie puede garantizar que vayan a dar ningún resultado tangible en los próximos años. Paralelamente, otro grupo de autores ha aducido que, aun cuando finalmente estas técnicas resultaran fiables, su campo de aplicación sería demasiado estrecho como para justificar todo el esfuerzo realizado ${ }^{54}$. Este problema, que es similar al que ya hemos expuesto en el caso de las terapias génicas sobre células somáticas, cobra en esta ocasión todavía mayor importancia, ya que la posibilidad de obtener frutos tangibles es aún más remota. Por eso mismo, nos permitiremos reiterar aquí, con el necesario reforzamiento, todo lo ya dicho en torno a la quiebra del principio de justicia que ya enunciamos anteriormente, y que se encuentra directamente relacionado con la asignación de recursos en el sistema sanitario.

En un sentido parecido, aunque tal vez desde una perspectiva un tanto más pragmática, hay quienes nos recuerdan que, dado que algunos de estos genes no son, en realidad, estrictamente nocivos o, al menos, no lo 
son en todos los casos, no es fácil saber qué ocurrirá en el futuro con la especie humana si eliminamos lo que, en realidad puede ser un factor de desarrollo evolutivo. De hecho, parece bastante probable que la introducción de esta clase de terapias podría acabar con la capacidad de evolucionar de la especie humana, al menos mediante el tradicional vehículo de las mutaciones accidentales. Así, no estaría de más pararnos a pensar un momento que si permitiéramos a una ciencia como la medicina que, de por sí, es sumamente conservadora, alterar cualquier signo anómalo, lo más probable es que, al final, no queden espacio para las mutaciones que, no lo olvidemos son un factor evolutivo esencial ${ }^{55}$. El riesgo de este proceder es que, inevitablemente, acabemos homogeneizando el patrimonio genético de todo ser humano con respecto al de sus semejantes. En consecuencia, el desarrollo de estas técnicas nos impediría seguir con el curso natural del procedimiento evolutivo, abriéndose así ante nosotros el grave problema de permanecer estancados desde esta perspectiva. Cabe, por supuesto, aducir, que, en realidad, no estaríamos destruyendo el proceso evolutivo sino, más bien, dirigiéndolo. Sin embargo, la propia perspectiva de que sea el hombre quien decida hacia donde evolucionar abre perspectivas que, a nuestro juicio, pueden hallarse demasiado cercanas a los manejos de la ingeniería genética.

En conclusión, creemos que la única solución sensata en lo que se refiere a la terapia génica sobre la línea germinal debe ser su prohibición temporal, al menos hasta el momento en que dispongamos de datos suficientes para evaluar los auténticos riesgos que pude conllevar su puesta en funcionamiento. En este sentido, sería más que recomendable una supervisión estricta de los experimentos que se realicen en este campo. De lo contrario, y por desgracia, nos tememos que la consecución de algún avance en torno a estas técnicas en el ámbito de laboratorio implicará inevitablemente una posibilidad real de puesta en práctica muy difícil de evitar y que puede ocasionarnos graves consecuencias en un futuro ${ }^{56}$. La solución óptima, por tanto, se situaría, desde nuestro punto de vista, en una moratoria sobre el uso de estas terapias que, en todo caso, no excluyera su 
utilización en un escenario futuro en el que los riesgos a los que ahora nos enfrentamos hayan desaparecido ${ }^{57}$. Esta autorización, no obstante, debería contar con el consentimiento de la sociedad en su conjunto, sin que ello, a nuestro juicio, supusiera en ningún momento un quebrantamiento injustificado del principio de autonomía, por cuanto mientras la manipulación genética de células somáticas entraba dentro de la esfera de la elección personal, la que se refiere a las células germinales escapa de ese reducto, extendiendo su campo de acción hacia toda la humanidad. Por eso mismo, la autorización final para su aplicación ha de ser, a todas luces, supraindividual y, muy probablemente, supranacional.

\section{7.- LEGISLACIÓN APLICABLE}

Entrando ya a lo que se refiere al estudio de las normas positivas que ahora mismo existen en torno al tema de las terapias génicas, lo primero que debemos señalar es que, si por algo se caracteriza la legislación actual es, precisamente, por su escaso volumen, cosa que tampoco debe resultarnos demasiado extraña. Tanto lo novedoso de estas técnicas como su todavía escasa incidencia son motivos más que suficientes para entender que el Derecho, que habitualmente camina siempre un paso más atrás que la ciencia, no haya entrado todavía plenamente a regular estas materias.

Hay que señalar, no obstante, que algunos de los documentos más importantes de entre todos los que se han aprobado en el ámbito internacional en los últimos años, en lo que al tema de la Bioética atañe, incluyen entre sus cláusulas algunas previsiones en torno a la puesta en práctica de las terapias génicas.

Así, y dentro del marco de la UNESCO, la Declaración Universal sobre el Genoma Humano y los Derechos Humanos de 11 de noviembre de 1997, ha enunciado los siguientes principios:

La investigación, el tratamiento, y la diagnosis de una patología se han de realizar sólo después de un riguroso asesoramiento previo acer- 
ca de los riesgos y los beneficios obtenibles (art.5a). Deberán realizarse en beneficio de la persona objeto de dichas prácticas, salvo en casos excepcionales (art. 5e)

En cualquier caso, y para la realización de cualquiera de las actividades enunciadas en el párrafo anterior, es necesario obtener un consentimiento informado y libre por parte del paciente o, en caso de que éste no se halle en condiciones de otorgarlo, de aquellos que lo representen (art $5 \mathrm{~b}$ y $5 \mathrm{e})$

Toda persona tiene derecho a decidir si quiere ser informado o no de los resultados de los exámenes genéticos y de sus consecuencias (art.5c).

Nadie podrá ser sometido a discriminación por sus características génicas (art. 6).

Se deberá proteger la confidencialidad de los datos obtenidos con fines de investigación o cualquier otra finalidad (art. 7).

Toda persona tiene derecho a ser indemnizada de cualquier daño ocasionado por una intervención sobre su genoma (art. 8).

La investigación no prevalecerá jamás sobre el respeto a los derechos humanos, las libertades fundamentales y la dignidad humana (art. 10)

Los beneficios de la investigación deben estar disponibles para todos los seres humanos por igual (art. 12a)

La libre investigación debe ser garantizada por los diferentes Estados (art. 12b)

En segundo lugar, debemos citar al Consejo de Europa, en cuyo marco de actuación debe situarse un documento tan importante como la Convención para la Protección de los Derechos Humanos y la Dignidad del Ser Humano con respecto a las aplicaciones de la Biología y la Medicina, también llamado Convenio de Oviedo. Entre los puntos fundamentales de este segundo documento destacaremos los siguientes:

Respeto a la privacidad en la información. Toda persona tiene el derecho a conocer la información obtenida sobre uno mismo y, al mismo tiempo, derecho a no conocerla (art.10). 
Principio de no discriminación de las personas por su herencia genética (art. 11).

Los test genéticos sólo podrán efectuarse por motivos relacionados con la salud, y susceptibles de un consejo genético apropiado (art. 12)

Prohibición de cualquier intervención en la línea germinal. Limitación de las intervenciones en la línea somática a propósitos preventivos, diagnósticos o terapéuticos (art. 13)

También dentro del ámbito del Consejo de Europa, debemos citar la Recomendación 1512, adoptada por el la Asamblea Parlamentaria en el año 2001, y contestada por el Consejo de Ministros el 12 de junio de 2002. Entre sus principales puntos se encuentran los siguientes:

Respeto a la dignidad humana. Ha de ser la dignidad el principio básico que guíe el desarrollo del Proyecto Genoma Humano.

En lo que respecta a los test y al barrido génico por propósitos de salud, se remite al Convenio de Oviedo. Se prohibe realizar estudios genéticos si no van a ir acompañados de un beneficio para la salud de aquellos que se someten a dichas prácticas, $o$, al menos, de medidas que permitan minimizar el riesgo de contraer la enfermedad que se intenta detectar.

Principios que deben guiar la investigación de los datos genéticos: beneficencia, igualdad de acceso (justicia), buena práctica, y fundamento práctico (evidence based).

Se anima al desarrollo de la medicina preventiva basada en la investigación génica.

Se considera que no hace falta la creación generalizada de comités de ética porque ya existen.

De otro lado, se recomienda encarecidamente evitar la duplicación de esfuerzos, mediante una labor de coordinación adecuada por parte de todos los países miembros del citado foro.

Se recomienda la elaboración de campañas informativas generalizadas, aunque especialmente destinadas a los profesionales sanitarios. 
ANDLERSON, W. F., "El tratamiento de las enfermedades hereditarias", Mundo Cientifico, $1989, n^{\circ} 6$.

BERCER, E. M. y B. M. GERT, "Genetic Disorders and the Ethical Status of Germ-Line Gene Therapy", Journal of Medicine and Philosophy, vol. 16.

BORDICNON, C. et als., "Gene Therapy in Peripheral Blood Lymphocytes and Bone Narrow for ADA-Inmunodeficient Patients", Science, $n^{\circ} 270,1995$.

CANGLILHEM, G., Lo nomal y lo patológico, México: Siglo XXI, 1986.

CAVAZZANA-CALVO, M. et als, "Gene Theraphy of Human Severe Combined Immunodeficiency (SDIC)-Xi Disease", Science, n²87, 2000.

CHADWICK, R., "Gene Therapy", en SINGER, P. y H. KUHSE, A companion to Bioethics.

COCHLAV, A., "Gene dream fades Hawai", New" Scientist, 25 de noviembre de 1995.

COCHLAN, A., "Gene shuttle virus could damage the brain", New Scientist, 11 de mayo de 1996.

DAVIES, K., La Conquista del Genoma Humano. Barcelona: Círculo de Lectores, 2001.

DAVIS, B. D, "Limits to genetic intervention in humans: somatic and germ line, en CHADWICK, $R$. et als. (Eds.), Human genetic Information: Science, law and ethics, Chistester: John Wiley, 1990.

DUSSE'T, J., "Medicina predictiva", en A. A. V. V . El Genoma Humano, Madrid: Consejo de Europa, 2002.

ELIZARI, F. J., Bioethics, St. Pauls, 1994.

FEITO, L. Bioética y terapia génica, Madrid: LPCO, 1999.

CAFO, J, Problemas éticos de la manipulación genética, Madrid: ediciones Paulinas, 1992.

GURA, T., "Repairing the Genome's Spelling Mistakes", Science, no285, 1999.
HO, M. W., Ingenieria Genética: isueño o pesadilla?’, Barcelona: GEDISA, 2001.

HODGSON, "There's a whole lot of nothing going on", Biotechnology, nº13, 1995.

HOLTUG, N., "Human Gene Therapy: Down the slippery slope", Bioethics, n 7, 1993.

HUBBARD, R. y WALD, E., El mito del gen, Madrid: Alianza Lillitorial, 1999.

JANE, S. M., J. M. CUNNINGHAM et als, "Vector development: a major obstacle in human gene therapy", Annals of Medicine, $\mathrm{n}^{0} 30,1998$.

KMIEC, E.. "Gene Therapy", American Scientist, $n^{\circ} 87,1999$.

LACADENA, J. R., "Bioética, gratuidad del organismo y patentabilidad de los genes humanos", Moralia, n²0, 1990.

LACADENA, J. R., "Las intervenciones en el Cenoma Humano: un enfoque genético", en ROMEO CASABONA, C. M. (Ed.), Genética y Derecho Penal, Granada: Comares, 2001.

LEROI, W., "IThe ethics of human gene therapy", Nature, 1986, n³20.

MAVARNACHE, R., "Terapia génica", en $\Lambda . \Lambda . V$. $\checkmark$., Bil Genoma Humano, Madrid: Consejo de Europa, 2002.

MARSHALL, E., E. PENNISI y L. ROBERTS, "In the Crossfire: Collins on Genomes, Patents and Rivalry", Science, $n^{\circ} 287,2000$.

MASON, J. K. y R. A. McCALL SMITH, Law and Medical Ethics, Butterworths, 1999.

MULLICAN, R. C.. "The basic science of gene: therapy", Science, n"260, 1993.

MUÑOZ, E., Biotecnología y sociedad. Encuentros y desencuentros, Madrid: Cambridge University Press, 2001.

MUÑOZ, E., Biotecnologia y sociedad. Encuentros $y$ desenruentros, Madrid: Cambridge University Press, 2001. 
MURRAY, 'T. H., "Ethical issues in human genome research", en BULGER, R. E. et als (Eds), The Ethical Dimensions of the Bilogical Sciences, Cambridge University Press, 1993.

PLTNAM, L., "Debate grows on safety of gene.therapy vectors", The Lancet, $n^{0} 351,1998$.

RIFKIN, J., El siglo de la biotecnologia, Barcelona: Crítica, 1999.

SÁDABA, J., y J. L. VELÁZQUEZ, Niños a la carta, Madrid: Temas de Hoy, 1998.

SANTOS, A., Instrumentación genética, Madrid: palabra, 1987.

SILBERNER, J., "A Gene Therapy Death", Hastings Centre Report, vol. 30, $\mathrm{n}^{\circ} 2,2000$.

SINGER, P. y H. KLHSE, $A$ companion to Bioethics, Oxford: Balckwell, 1998.

VERMA, I., "Terapia génica", Scientific American, $\mathrm{n}^{\circ} 263,1990$.

WALTERS, L., "The ethics of human gene therapy", Nature, $\mathrm{n}^{\circ} 298,1986$.

WILLIAMSON, B., "Gene Therapy", Nature, $\mathrm{n}^{\circ}$ 298, 1982.

ZIMMERMAN, B. E., "Human Germ-Line

Therapy: The Case for its Development and Lse", Journal of Medicine and Philosophy, diciembre de 1991.
1 En este caso, por tanto, el diagnóstico génico funcionaría como una suerte de medicina predictiva, pero sería la medicina tradicional quien fijara los parámetros de actuación posteriores. Véase, en torno a este tema: DLSSET, J., "Medicina predictiva", en A. A. V. V ., El Genoma Humano, Madrid: Consejo de Europa, 2002, págs. 75 y ss.

2 Este es, precisamente, el título de una de las obras de SÁDABA y VELÁZQUEZ dedicadas a la Bioética (Cfr: SÁDABA, J., y J. L.

VELAZZLEZ, Niños a la carta, Madrid: Temas de Hoy, 1998, título).

3 Cfr: RIFKIN, J., El siglo de la biotecnologia, Barcelona: Crítica, 1999, pág. 127) SÁDABA y VELÁZQUEZ la caracterizan como los "cambios artificialmente introducidos en los genes de una célula (Cfr: SÁDABA, J., y J. L. VELÁZQUEZ, Niños a la carta, cit, pág. 145). HO, por su parte, define a la ingeniería genética como un "conjunto de técnicas para aislar, modificar, multiplicar y recombinar los genes de diferentes organismos" (Cfr: HO, M. W., Ingenieria Genética: ¿sueño o pesadilla?", Barcelona: GEDISA, 2001, pág. 45). ELIZARI, como la mezcla de técnicas que permite intervenir en la información genética a nivel de estructuras moleculares y mecanismos implicados en la transmisión de la herencia (Cfr: ELIZARI, F. J., Bioethics, St. Pauls, 1994, pág. 166).

4 Lo cual, por supuesto, no significa que esta distinción sea fácil de trazar, entre otras cosas porque todavía no tenemos nada claro qué es una patología y qué no lo es. Así, por ejemplo, no está nada claro si efectuar una intervención sobre los genes que intente reducir la tendencia a la obesidad de una persona es una actuación terapéutica o meramente eugenésica. Si intenta curar o, más bien, mejorar.

5 La definición insertada proviene de: LACADENA, J. R., "Terapia génica", Genética y bioética, C.N.I.C.E., en Internet: 
www.cnice.mecd.es/genetica/1999 04/19990

4. 00.html. También puede hallarse en:

LACADENA, J. R., "Las intervenciones en el Genoma Humano: un enfoque genético", en ROMEO CASABONA, C. M. (Ed.), Genética y Derecho Penal, Granada: Comares, 2001, pág.8 y en: LACADENA, J. R., "Bioética, gratuidad del organismo y patentabilidad de los genes humanos", Moralia, n"20, 1990, págs. 441462. Otra definición más amplia de terapia génica extraída de la misma fuente es la siguiente: "técnica terapéutica mediante la cual se inserta un gen funcional en las células de un paciente humano para corregir un defecto genético o para dora a las células de una nueva función"

6 Ello no obstante, y como tendremos ocasión de exponer en nuestro siguiente apartado, es posible que esta última afirmación deba ser modificada en un breve intervalo de tiempo.

7 Cfr: MANARNACHE, R., "Terapia génica", en A. A. V. V ., El Genoma Humano, Madrid: Consejo de Europa, 2002, pág. 95.

8 Cfr: RIFKIN, J., El siglo de la biotecnología, cit., pág. 128.

9 Cfr: RIFKIN, J., El siglo de la biotecnología, cit., pág. 128 y 129.

10 Por otra parte, hubo quienes apuntaron que la niña Ashanti DESILVA se había sometido, ya antes de que le fuera aplicada la terapia génica, a un tratamiento convencional llevado a cabo con fármacos que habían conseguido ya que los niños que padecían esta patología no tuvieran que vivir bajo la burbuja protectora que da nombre a la enfermedad (Véase: MARATZ, R., "Dr. Anderson's Gene Machine", New York Times Magazine, 31 de marzo de 1991, págs. 30-35 y 50; HUBBARD, R., El mito del gen, cit., pág. 194).

11 Cfr: BORDIGNON, C. et als., "Gene Therapy in Peripheral Blood Lymphocytes and Bone Narrow for ADA-Inmunodeficient Patients", Science, n²70, 1995, págr. 470-475.
12 El experimento en cuestión partía de una terapia ex vivo inventada por el ya mencionado WILSON, quien extirpaba un trozo de hígado al paciente apara introducir un gen sano en las células hepáticas asi obtenidas.

Posteriormente, esas células eran inyectadas de vuelta en el cuerpo del paciente. Si bien los primeros resultados parecieron satisfactorios, a la larga el experimento no prosperó (Cfr: DAVIES, K., La Conquista del Genoma Humano, Barcelona: Círculo de Lectores, 2001, pág. 293).

13 Cfr: MANARNACHE, R., "Terapia génica", en A. A. V. V ., El Genoma Humano, cit., pág. 96 y ss.

14 Véase: MUN̄OZ, E., Biotecnología y sociedad. Encuentros y desencuentros, Madrid:

Cambridge University Press, 2001, pág. 153; COGHLAN, A., "Gene dream fades Hawai", New Scientist, 25 de noviembre de 1995, págs. 14 y 15; HODGSON, "There's a whole lot of nothing going on", Biotechnology, n'13, 1995, pág. 714.

15 Cfr: DAVIES, K., La Conquisia del Genoma Humano, cit., pág. 294; COGHLAN, A., "Gene shuttle virus could damage the brain", New Scientist, 11 de mayo de 1996, pág. 6.

16 Cfr: SILBERNER, J., "A Gene Therapy Death", Hastings Centre Report, vol. 30, $\mathrm{n}^{0} 2,2000$, pág. 6.

17 Véase: CAVAZZANA-CALVO, M. et als, "Gene Theraphy of Human Severe Combined Immunodeficiency (SDIC)-Xi Disease",

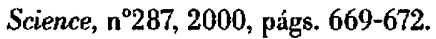

18 En este caso, se trataba de cinco niños menores de un año.

19 Cfr: DAVIES, K., La Conquista del Genoma Humano, cit., pág. 295.

20 Cfr: LACADENA, J. R., "Terapia génica", Genética y bioética, C.N.I.C.E., en Internet: www.cnice.mecd.es/genetica/1999 04/1999 0 4. $00 . \mathrm{html}$ 
21 Cfr: HO, M. W., Ingeniería Genética: isueño o pesadilla?", cit., pág. 280; GRACE, E. S., $L a$ biotecnología al desnudo. Promesas y realidades, cit., pág. 92 . Algunas de las patologías para las que se están utilizando los retrovirus son el cáncer, la SIDA, la hipercolesterolemia familiar o la inmunodeficiencia combinada severa (Cfr: LACADENA, J. R., "Terapia génica", Cenética $y$ bioética, C.N.I.C.E., en Internet: www.cnice.med.es/genetica/1999 04/1999 0 4. 00.html)

22 MANARANCHE, R., "Terapia génica", en A. A. V. V , El Genoma Humano, Madrid: Consejo de Europa, 2002, págs. 102 y ss.

23 Cfr: MUÑOZ, E., Biotecnología y sociedad. Encuentros y desencuentros, Madrid: Cambridge University Press, 2001, pág. 155 y ss; HUBBARD, R. y WALD, E., El mito del gen, Madrid: Alianza Editorial, 1999, pág. 192. Entre las patologías para las que se utilizan los liposomas se halla la fibrosis quística o el enfisema pulmonar (Cfr: LACADENA, J. R., "Terapia génica", Genética y bioética, C.N.I.C.E., en Internet: www.cnice.mecd.es/genetica/1999 04/19990 4. 00.html).

24 Cfr: DAVIES, K., La Conquista del Genoma Humano, cit, pág. 295; SILVER, L. M., Vuelta al Edén, cit., pág. 314.

25 Cfr: MUÑ̃Z, E., Biotecnologia y sociedad. Encuentros y desencuentros, cit., pág. 154.

26 Véase: LACADENA, J. R., "Terapia génica", Genética y bioética, C.N.I.C.E., en Internet: www.cnice.mecd.es/genetica/1999 04/1999 0 4 00.html; LÓPEZ MORATALLA, N. y 1 . GONZÁLEZ DE LA TEJADA, "Potencial terapéutico de las células madre humanas", en Internet: www.arvo.net; MULLIGAN, R. C., "The basic science of gene therapy", Science, n²60, 1993, págs. 926-932.

27 Cfr: LACADENA, J. R., "Terapia génica", Genética y bioética, C.N.I.C.E.., en Internet: www.cnice.mecd.es/genetica/1999 04/1999 0 $4.00 . h \mathrm{tml}$

28 Cfr: MUN̄OZ, E., Biotecnologia y sociedad. Encuentros y desencuentros, cit., pág. 154.

29 Cfr. LACADENA, J. R., "Terapia génica", Genética y bioética, C.N.I.C.E., en Internet: www.cnice.mecd.es/genetica/1999 04/1999 0 4 00.htuml; VERMA, I., "Terapia génica", Scientific American, n²63, 1990, púgs. 34-4l. El problema, hasta ahora al menos, es que no ha resultado posible encontrar un método con el que conseguir que los genes alterados lleguen sanos y salvos a sus objetivos en el cuerpo, y controlar la expresión de los genes en las células modificadas (Cfr: GRACE, E. S., La biotecnologia al desnudo. Promesas y realidades, cit., pág. 101).

30 Cfr: KMILC, E., "Gene Therapy", American Scientist, n87, 1999, págs. 68-73; GURA, T., "Repairing the Genome's Spelling Mistakes", Science, n²85, 1999, págs. 316-318.

31 Cfr: RIFKIN, J., El siglo de la biotecnologia, cit., pág. 128; HUBBARD, R., El mito del gen, cit., pág. 196 y ss; MASON, J. K. y R. A. McCALL SMITH, Laui and Medical Ethics, Butterworths, 1999, pág. 184.

32 Cfr: FElTO, L. Bioética y terapia génica, Madrid: LPCO, 1999, pág. 248 y ss; SILVER, L. M., Vuelta al Edén, cit., pág. 317 .

33 De hecho, el citado RIFKIN llama a la era de la manipulación genética como la era de la “algenia", palabra que él extrae claramente del vocablo "alquimia", utilizado, precisamente, para definir las prácticas pseudocientíficas propias de la Edad Media (Cfr: RIFKIN, J., El siglo de la biotecnologia, cit., pág. 46 y ss)

34 Cfr: FEITO, L. Bioética y terapia génica, cit., pág. 250.

35 Un extenso catálogo de todos los riesgos posibles puede hallarse en: HO, M. W., Ingeniería Genética: ¿sueño o pesadilla?’, cit., 
pág. 289 y 88 . Véase también: SHIVA, V., Biopiratería, Barcelona: lcaria, 2001, pág. 55.

36 Véase, en este sentido: FEITO, L. Bioética y terapia génica, cit., pág. 294 y ss; ROTHMAN, B. K., Genetic Maps and Human Imaginations, cit. pág. 177 .

37 Como indica Ruth HUBBARD, "los tratamientos pueden ser un ser un beneficio real, pero, desafortunadamente, la alta tecnologia merma los recursos destinados a medidas médicas y de salud social que podrian mejorar la salud de un número mucho mayor de personas" (Cfr: HUBBARD, R., El mito del gen, cit., pág. 196).

38 Este tipo de consideraciones tuvieron especial predicamento a finales de los $\mathbf{9 0}$, cuando alguien tan poco sospechoso de reticente hacia las terapias génicas como COLLINS, reconoció abiertamente, en un artículo publicado en la revista Science, los decepcionantes resultados obtenidos hasta entonces por todo este tipo de tratamientos experimentales (Cfr: MARSHALL, E., E. PENNISI y L. ROBERTS, "In the Crossfire: Collins on Genomes, Patents and Rivalry", Science, n²87, 2000, págs. 2396-2398). A esta misma conclusión llegó un examen de los ensayos clínicos llevados a cabo durante cinco años con más de 597 pacientes en Estados Unidos (Cfr: RIFKIN, J., El siglo de la biotecnología, cit., pág. 130).

39 Ello no obstante, desde algunas instancias se ha apuntado la posibilidad de que los vectores de la terapia génica no sean realmente seguros, y cabe que generen efectos nocivos en la célula (Cfr: HO, M. W., Ingeniería Genética: ¿sueño o pesadilla?", cit., pág. 281; JANE, S. M., J. M. CUNNINGHAM et als, "Vector development: a major obstacle in human gene therapy", Annals of Medicine, $\mathrm{n}^{\circ} 30,1998$, págs. 413-415; PUTNAM, L., "Debate grows on safety of gene.therapy vectors", The Lancet, $\mathrm{n}^{\circ} 351$, 1998, pág. 808.
40 Cfr: HLBBARD, R., El mito del gen, cit., pág. 192.

41 Véase: ANDERSON, W. F., "El tratamiento de las enfermedades hereditarias", Mundo Cientifico, 1989, $n^{\circ} 6$, pág. 630. Lin recorte en la investigación de este tipo de terapias podría, en cualquier caso, contravenir lo dispuesto en el artículo 12 a) de la Declaración Universal de la UNESCO sobre el Genoma Humano y los Derechos Humanos de 11 de noviembre de 1997, que prclama que "toda persona debe tener acceso a los progresos de la biología, la genética y la medicina en materia de genoma humano, respetándose su dignidad y derechos".

42 Lo cual, como ya hemos explicado, no significa que, a largo plazo, el desarrollo de estas terapias no puedan ser un negocio más que rentable para nuestros sistemas sanitarios.

43 La aceptación de las terapias génicas en la línea somática es, por otra parte, mayoritaria en la literatura (Cfr: LACADENA, J. R., "Terapia génica", Genética y bioética, C.N.I.C.E., en Internet: www.enice.mecd.es/genetica/1999 04/1999 0 4 00.html; GRACle, E. S., La biotecnología al desnudo. Promesas y realidades, cit., pág. 258 y ss; SANTOS, A., Instrumentación genética, Madrid: palabra, 1987, pág. 229 y 230; SINGER, P. y H. KUHSE, $A$ companion to Bioethics, Oxford: Balckwell, 1998, pág. 191; ELIZARI, F. J., Bioética, cit., pág. 165). De la misma forma, cabe resaltar que ya en 1984, y en el seno de la Office of Technology Assesment se logró ya un consenso entre especialistas en cuestiones éticas, teólogos y otras autoridades religiosas en torno a este tcma, siluando este tipo de técnicas dentro de la línea correcta dc actuación médica (Cfr: GaRCÍA MIRANDA, C. M., Perspectiva ética y juridica del Proyecto Genoma Humano, cit., pág. 38).

44 En este sentido, nos permitiremos reproducir las inquietantes palabras de Ruth CHADWICK, 
quien manifiesta que "es concebible que la células que se introducen en el cuerpo gracias a técnicas de terapia somática (por ejemplo, a través de un virus utilizado para transportar genes al interiore del cuerpo) puedan recombinarse con otros virus e infectar las células germinales" (Cfr: CHADWICK, R., "Gene Therapy", en SINGER, P. y H. KLHSE, $A$ companion to Bioethics, cit., pág. 189. Traducción del autor). Véase también: ROMEO CASABONA, C. M., El Derecho y la Bioética ante los límites de la vida humana, cil., pág. 366.

45 Slippery slop.

46 Cfr: ZIMMERMAN, B. E., "Human Germ-Line Therapy: The Case for its Development and Use", Journal of Medicine and Philosophy, diciembre de 1991, pág. 594 y ss.

47 Cfr: LEROI, W., "The ethics of human gene therapy", Nature, 1986, n 320 , págs. 225-227; GRACE, E. S., La biotecnología al desnudo. Promesas $y$ realidades, cit., pág. 258; CHADWICK, R., "Gene Therapy", cit., pág. 189; DAVIS, B. D, "Limits to genetic intervention in humans: somatic and germ line, en CHADWICK, R. et als. (Eds.), Human genetic Information: Science, law and ethics, Chistester: John Wiley, 1990, pág. 84.

48 Esta afirmación fue apuntada anteriormente por WALTERS (Cfr: WALTERS, L., "The ethics of human gene therapy", Nature, $n^{\circ} 298,1986$, págs. 225-227). En sentido contrario, LACADENA ha manifestado que este cambio ya se está produciendo con el avance de la medicina, y que eso no debe impulsurnos a pararlo y, por otra parte, es demasiado lento para ser tenido en cuenta (Cfr: LACADENA, J. R., "Manipulación genética", en GAFO (Ed.) Fundamentación de la Bioética y manipulación genética, Madrid: UPCO, 1989, pág. 170.

49 Cfr: RIFKIN, J., El siglo de la biotecnologia, cit., pág. 131. Véase también: FRIEDMANN, T., "Progress toward human gene therapy", eit., págs. 1275-1281.
50 Cfr: RIFKIN, J., El siglo de la biotecnologia, cit, pág. 131; HUBBARD, R., El milo del gen, cit., pág. 200; GRACE, E. S., La biotecnología al desnudo. Promesas y realidades, cit., pág. 258.

51 Cfr: WILLIAMSON, B., "Gene Therapy", Nature, $\mathrm{n}^{\circ} 298,1982$, págs. 416-418; CHADWICK, R., "Gene Therapy", cit., pág. 191.

52 Cfr: LACADENA, J. R., "Terapia génica", Genética y bioética, C.N.I.C.E., en Internet: www.cnice.mecd.es/genetica/1999 04/1999 O 4 00.himl; MURRAY, T. H., "Ethical issues in human genome research", en BULGER, R. E. et als (Eds), The Ethical Dimensions of the Bilogical Sciences, Cambridge University Press, 1993, pág. 289; ROMEO CASABONA, C. M., El Derecho y la Bioética ante los límites de la vida humana, cit., pág. 367 y 368 ; Conclusión $n^{0} 6$ de la Declaración de Bilbao en el "Encuentro Internacional sobre el Proyecto Genoma Humano", celebrado del 23 al 26 de mayo de 1993 en Bilbao.

53 Así, por ejemplo, el mismo gen que provoca la fibrosis quística cuando funciona como dominante, permite a quienes lo poseen como recesivo una mayor resistencia frente a enfermedades como la malaria. Como dice HUBBARD, "debemos recordar que un mismo gen puede funcionar de forma diferente en distintos tejidos. El hecho de que los científicos hayan asociado una secuencia de ADN con un carácter específico no significa que dicha secuencia no tenga otras funciones. Podría participar en otra reacciones metabólicas de las que los científicos no sepan nada. Alterar el ADN tendrá efectos inesperados, y hay motivos para creer que algunos de ellos serán indeseables" (Cfr: HUBBARD, R., El mito del gen, cit., pág. 199).

54 Cfr: HUBBARD, R., El mito del gen, cit., pág. 198.

55 Cfr: CANGUILHEM, G., Lo normal y lo patológico, México: Siglo XXI, 1986, pág. 89. 
$56 \mathrm{Y}$ es que, como muy bien apuntaban CERGER y GERT, "es muy probable que si se permitiera la terapia génica en la línea germinal, ésta se usaría inapropiadamente... En el mundo real los investigadores sobreestimarían su conocimiento sobre los riesgos intrínsecos del procedimiento y, por tanto, estarian tentados de usar terapia génica en la línea germinal aun cuando su uso no estuviera justificado" (Cfr: BERGER, E. M. y B. M. GERT, "Cenetic Disorders and the Ethical Status of Germ-Line Gene 'Therapy", Journal of Medicine and Philosophy, vol. 16, págs. 667-683). De otro lado, hay quienes han manifestado su temor a que la puesta en práctica de estas terapias sea una primera vía de entrada para la ingeniería genética de mejora (Cfr: HOLTCG, N., "Human Gene Therapy: Down the slippery slope", Bioethics, n 7, 1993, pág. 402). En sentido contrario, véase: ELIZARI, F. J., Bioética, cit., pág. 165.

57 Véase: LACADENA, J. R., "Terapia génica", Genética y bioética, C.N.I.C.E., en Internet: www.cnice.mecd.es/genetica/1999 04/19990 4 00.html; GAFO, J, Problemas éticos de la manipulación genética, Madrid: ediciones Paulinas, 1992, pág. 215. 